Book Power in Communication, Sociology and Technology

Ed. Angela Repanovici, Manolis Koukourakis, Tereza Khecyoyan

Series: Philosophy, Communication, Media Sciences

Available online at http://trivent-publishing.eu/

\title{
The Level of Awareness on Scientometrics in Higher Education
}

\author{
Repanovici A., Koukourakis M.2, Alexandrescu M.B. ${ }^{3}$, \\ Cotoros D ${ }^{1}$., Rogozea L. ${ }^{1}$, Popa D. ${ }^{1}$ \\ ${ }^{1}$ Transilvania University of Brasov, Romania, arepanovici@unitbv.ro \\ 2University Library of Crete, Greece, manolis@lib.uoc.gr \\ ${ }^{3}$ Cultural Center for Social Welfare Brasov, Romania, alexa2bogdan@yahoo.com
}

\begin{abstract}
Following the plenary lecture presentation "Vision and Reality Regarding the Role of Bibliometrics in Scientific Research Evaluation" at an international conference, a new scientific research was initiated. The proposed questionnaire for gathering data was created in SurveyMonkey and was sent to all participants at the conference. The responses came from all over the world: Europe, Asia, Africa, South America and United States. The level of awareness regarding the importance of bibliometrics is high enough and absolutely necessary for libraries and research evaluation. Comments and suggestions are intriguing, interesting and represent an important source of inspiration for further approaches.
\end{abstract}

Keywords: Bibliometrics; scientometrics; scientific production; academic evaluation.

This is an Open Access article distributed in accordance with the Creative Commons Attribution Non Commercial (CC-BY-NC-ND 4.0) license, which permits others to copy or share the article, provided original work is properly cited and that this is not done for commercial purposes. Users may not remix, transform, or build upon the material and may not distribute the modified material (http:/ / creativecommons.org/ licenses/by-nc/4.0/) 


\title{
The Level of Awareness on Scientometrics in Higher Education
}

\author{
Angela Repanovici, ${ }^{1}$ Manolis Koukourakis, ${ }^{2}$ Mihai Bogdan Alexandrescu, ${ }^{3}$ \\ D. Cotoros, ${ }^{1}$ Liliana Rogozea, ${ }^{1}$ Daniela Popa ${ }^{1}$ \\ ${ }^{1}$ Transilvania University of Brasov, Romania \\ ${ }^{2}$ University Library of Crete, Greece \\ ${ }^{3}$ Cultural Center for Social Welfare Brasov, Romania
}

\section{Introduction}

Measuring information quality is an old and significant issue. The term statistical bibliographyseems to have been first used by E. Wyndham Hulme in 1922 when he delivered two lectures at the Sandars Reader in Bibliography at the University of Cambridge. Therefore, it is suggested that a better name forthis subject (as previously defined) is BIBLIOMETRICS, i.e. the application of mathematics and statistical methods to books and other media of communication.

Nalimo and Mulkenko defined Scientometrics as "the application of those quantitative methods which are dealing with the analysis of science viewed as an information process." 1

Scientometrics is defined as "the application of those quantitative methods which are dealing with the analysis of science viewed as an information process."

Nalimov's profound scientific works showed the world that our society needs to see far beyond our time dimension to change the situation of collapse and the disordered state of moral values. Nalimov's concepts of meaning and consciousness expand on a great variety of issues such as mathematics, philosophy, language, and psychology.

Important contributions in bibliometrics development were Lodka, ${ }^{2}$ Bradford, ${ }^{3}$ Gros \& Gros, ${ }^{4}$ Zipf, ${ }^{5}$ Derek de Solla $(1963-64)^{6}$, Eugene Grafield. ${ }^{7}$

Bibliometrics developed as a science being one of the analysis branch used in libraries for research and prediction. By the statistical analysis of the accepted number of papers, the development of a certain scientific domain could be proven.

Maine sources of bibliometric data are WOS, SCOPUS and GOOGLE SCHOLAR.

\footnotetext{
${ }^{1}$ Vasily Vasilevich Nalimov, Z. M. Mul'chenko, Наукометрия, Изучение развития науки как информачионного npoyecca [Naukometriya, the study of the development of science as an information process] (in Russian) (Moscow: Nauka, 1969), 191.

2 A. J. Lotka, "The frequency distribution of scientific productivity" Journal of the Washington Academy of Sciences 16(12) (1926): 317-324.

3 Samuel C. Bradford, "Sources of Information on Specific Subjects," Engineering: An Illustrated Weekly Journal (London) 137 (26 January) (1934): 85-86

${ }^{4}$ P.L.K. Gross, F.M. Gross, “College libraries and chemical education” Science 66 (1927): 386-389.

${ }^{5}$ G.K. Zipf, Human behaviour and the principles of least effort (Cambridge, MA: Addison-Wesley, 1949).

${ }^{6}$ Derek J. de Solla, Little science, big science (New York: Columbia University Press, 1963).

${ }^{7}$ E. Garfield, "Citation indexes for science: A new dimension in documentation through association of ideas" Science 122 (1955): 108-111.
} 
Citation and publication counts are derived from bibliometric databases (Web of Science - WOS, Scopus and to some extent from Google Scholar). More recently, bibliographic databases have also started to display citation counts of publications. ${ }^{8}$

The large part of the objectives and contexts where evaluation of research performance is conducted, productivity is either the most important or the only indicator that should inform policy, strategy and operational decisions. ${ }^{9}$ In research community authors form a social network, which is called Research Professionals' Collaboration Network. ${ }^{10}$

There are certain reactions in the academic community regarding the abusive use of scientometric indicators in academic evaluation and especially in the distribution of research funds. Thus, The Leiden manifesto for research metrics, and DORA-San Francisco Declaration on Research Assessment, occurred and promote academic attitudes leading to a single conclusion: these evaluations must be performed by experts, mainly by experts in information sciences.

All these information within the introduction were presented at the international prestigious conference QQML- Qualitative and Quantitative Methods in Libraries, during the $9^{\text {th }}$ edition that took place in Limerick, Ireland.

\section{Materials and methods}

Following the plenary lecture presentation "Vision and Reality Regarding the Role of Bibliometrics in Scientific Research Evaluation" at the QQML conference, a new scientific research was initiated in order to identify the importance of bibliometrics in research evaluation and also the representative bibliometric indicators in quantifying scientific production. The proposed questionnaire for gathering data was created in SurveyMonkey and was sent to all participants at QQML conference. The link to the questionnaire is: https://www.surveymonkey.com/r/92X28TG

\section{Analysis of survey results}

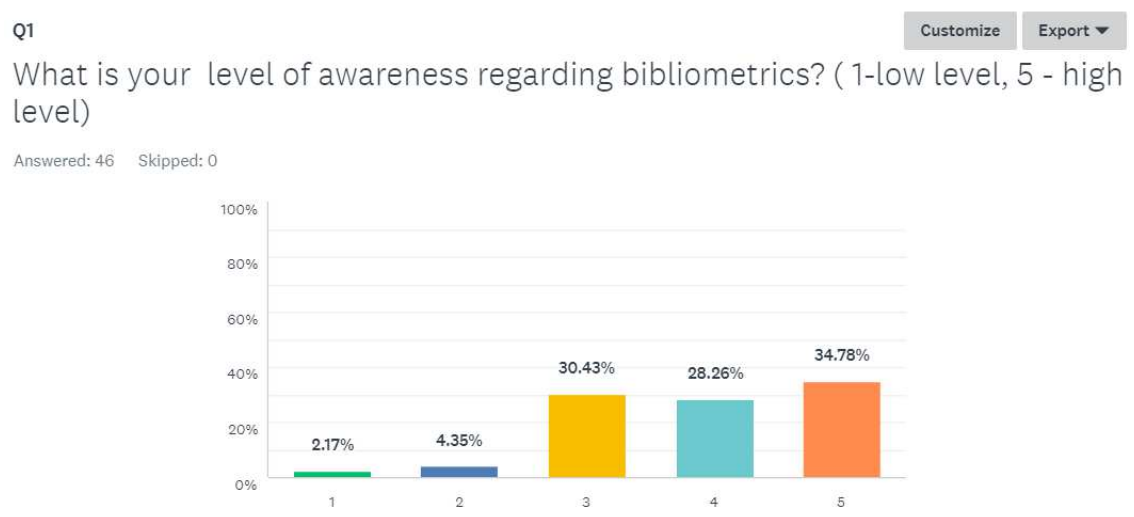

Fig. 1. Results regarding level of awareness in bibliometrics

\footnotetext{
8 James Wilsdon, Judit Bar-Ilan, Robert Frodeman, Elisabeth Lex, Isabella Peters, Paul Wouters, "Next-Generation Metrics" 26 (2017). doi: 10.12777/337729.

9 Giovanni Abramo and Ciriaco Andrea D'Angelo, "How Do You Define and Measure Research Productivity?” Scientometrics 101 (2) (2014): 1129-44. doi:10.1007/s11192-014-1269-8.

10 Anand Bihari, Manoj Kumar Pandia, "Key Author Analysis in Research Professionals' Relationship Network Using Citation Indices and Centrality.” Procedia Computer Science 57 (2015). Elsevier Masson SAS: 606-13. doi:10.1016/j.procs.2015.07.414.
} 
The level of awareness regarding bibliometrics and the fact that this level is the highest represents the opinion of $34,78 \%$ of the respondents, while $28 \%$ are aware of bibliometrics but not at the highest level and 30,43\% have an average level of awareness.2,75\% of the respondents consider that bibliometrics has no level of awareness while 4,35\% consider an average level of awareness regarding bibliometrics. (Fig. 1)

$56,72 \%$ of the respondents record a strong agreement regarding the fact that bibliometrics is very important for libraries and 32,61\% agree to that. A strong disagreement was expressed by $4,35 \%$ of the respondents while $6,53 \%$ neither agree nor disagree to the question. (Fig. 2)

\section{Q2}

\section{Is bibliometrics important for libraries?}

\section{Answered: 46 Skipped: 0}

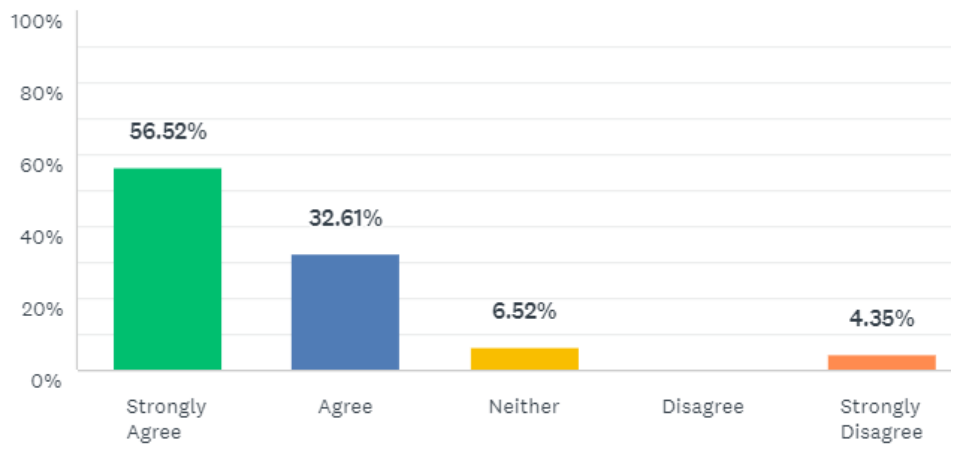

Fig. 2. Responses regarding the importance of bibliometrics for libraries

$52,17 \%$ of the respondents expressed a strong agreement regarding to the fact that bibliometrics is crucial and important in scientific research evaluation and 34,78\% simply agree to that. $8,7 \%$ do not agree, while 4,35\% neither agree, nor disagree. (Fig. 3)

Concerning the question whom is more important bibliometrics, 32,61\% of the respondents consider that bibliometrics is important for research evaluation, 2,71\% consider important for library and $65,22 \%$ for both. (Fig. 4)

$88,37 \%$ of the respondents consider that bibliometrics indicators are the most appropriate for appreciating scientific production. Only 6,98\% do not agree and 4,65\% do not know which indicators are more appropriate. (Fig. 5) 
Q3

Is bibliometrics important for research evaluation?

Answered: 46 Skipped: 0

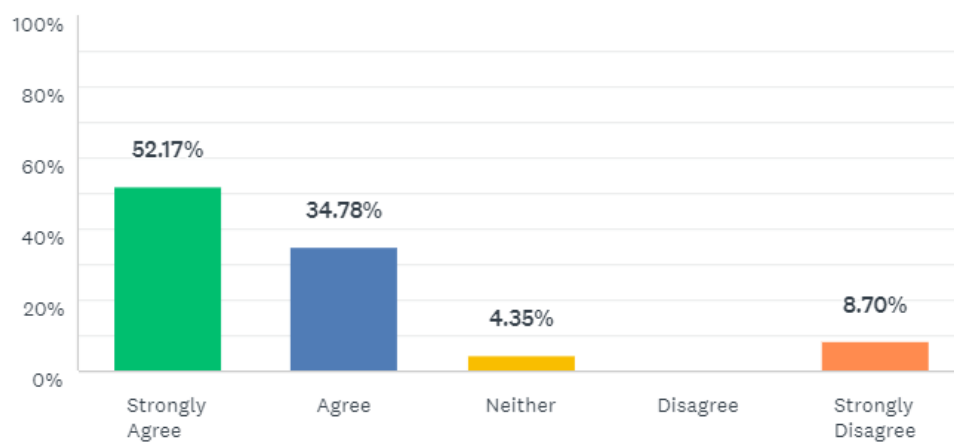

Fig. 3. Results concerning the importance of bibliometrics in research evaluation

Q4

For which of the two do you think it is more important?

Answered: 46 Skipped: 0

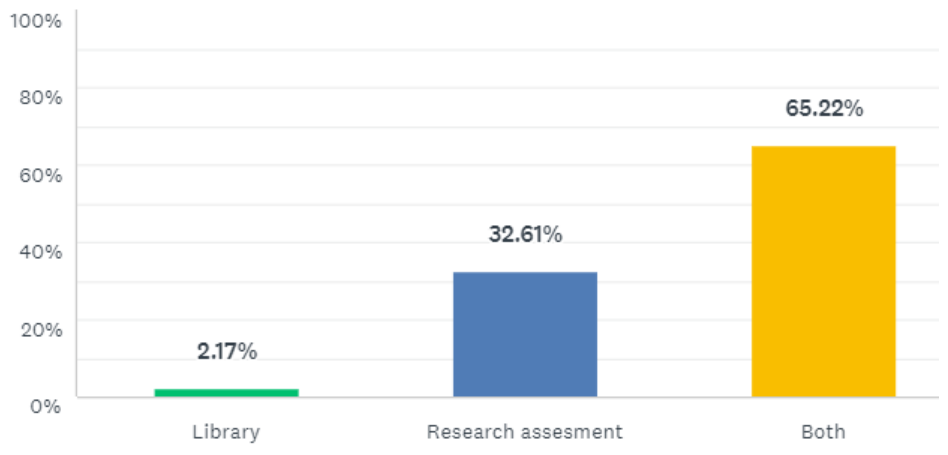

Fig. 4. Evaluation of importance given to bibliometric indicators 
Do you think that bibliometrics indicators are an appropriate way to measure scientific production?

Answered: 43 Skipped: 3

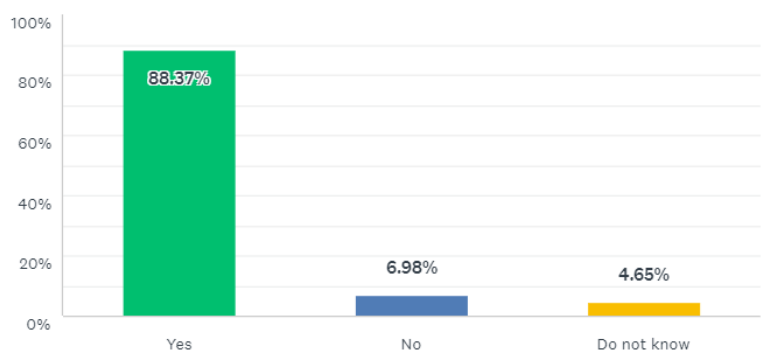

Fig. 5. Responses regarding the appropriateness of bibliometric indicators

There are various opinions in academic communities regarding the abusive use of bibliometric indicators in scientific production evaluation. This issue is highlighted also by the $55 / 33 \%$, result expressing the pro/against opinion that these indicators are adequate or not. (Fig. 6)

Q6 Customize Export -

Do you think that bibliometrics is appropriately use now for the evaluation of scientific production?

Answered: 45 Skipped: 1

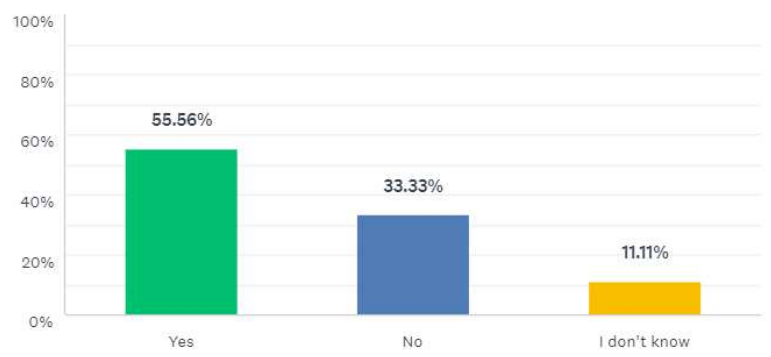

Fig. 6. Responses concerning the use of bibliometrics in scientific production evaluation

$95,65 \%$ of the respondents consider that Bibliometrics should be included as a subject in the LIS-Library and Information Science curricula. Only 2,17\% consider there is no need for that while 2,17\% do not know. (Fig. 7) 
Should use of bibliometrics tools be included in librarianship curricula?

Answered: 46 Skipped: 0

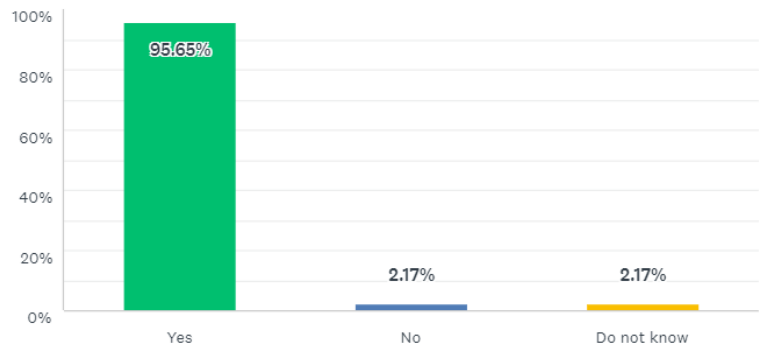

Fig. 7. Results regarding the inclusion of bibliometrics in LIS curricula

Bibliometrics services are offered by $50 \%$ of the institutions while in $50 \%$ of them, there are no such services. (Fig. 8)

Q8

Is there a bibliometrics service offered in your institution?

Answered: 46 Skipped: 0

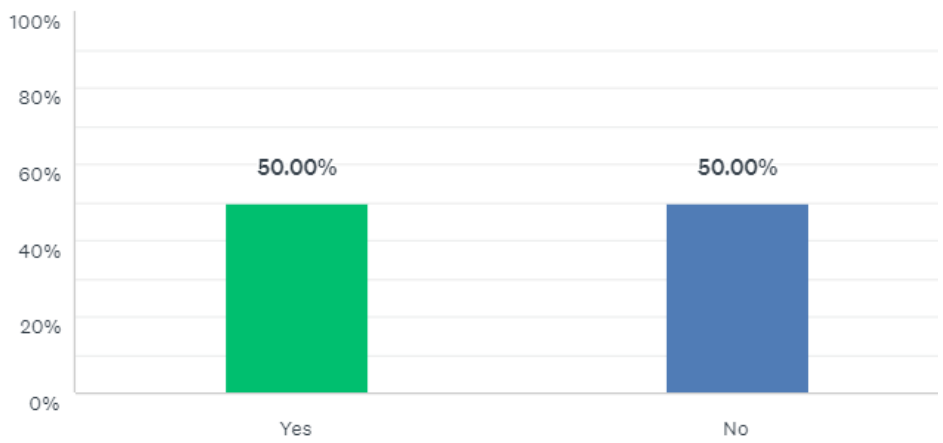

Fig.8. Responses regarding the bibliometrics services in institutions

$73,08 \%$ of the bibliometrics services are located in libraries and $26,92 \%$ are outside the libraries.(Fig. 9) 
Q9

If yes, is it part of the library or not?

Answered: 26 Skipped: 20

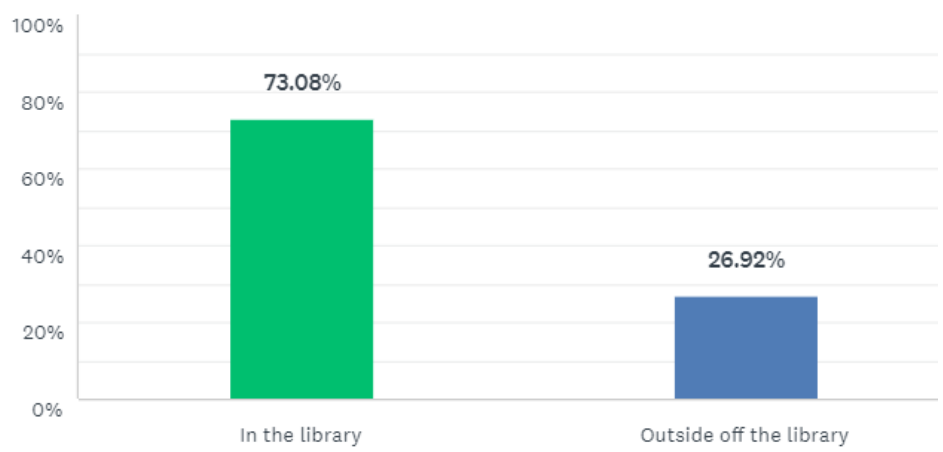

Fig. 9. Results regarding the location of the bibliometric services

Q10: If it is not part of the library which is its place in your institutional structure?

The fact that $73 \%$ of the bibliometrics services of the institutions are within the libraries shows a clear recognition of the fact that the experts in information science should be the ones offering these services.

Q11: Where do you think bibliometrics service should be appropriately affiliated?

The answer to the open question regarding the position of the bibliometrics services outside the library showed us that the departments responsible with the university projects or the department of scientific production or the science department or the research department or group of librarians are involved in bibliometrics research.

Q12: Your institution

The selected sample has a large geographic representation; all the continents are represented as shown in table 1 . (Table 1, Fig. 10)

Table 1. Geographic spread of the respondents

\section{Institution}

University of Crete Library, Greece

Limerick Institute of Technology, Ireland

University of Piraeus, Greece

Scientific Library of Balti Alecu Russo State University, Moldova

Federal University of Minas Gerais, Brazil

Transilvania University of Brasov, Romania

Academy of Public Administration, Yerevan, Armenia

Academy of Economic Studies of Moldova

Govt. Post graduate college for women satellite town Rawalo, USA

European University Institute - Florence, Italy

\section{Geographical} region

$\mathrm{EU}$

EU

$\mathrm{EU}$

Eurasia

South

America

$\mathrm{EU}$

Eurasia

Eurasia

USA

EU 
Federal University of Technology Owerri Imo State Nigeria

University of Minho, Portugal

Espirito Santo Federal University, Brazil

Zayed University, United Arab Emirates,

Netherlands Cancer Institute, Holland

University of Santo Tomas, Philippines

Alexander Technological Educational Institute of Thessaloniki-Greece

CIDEHUS - University of Évora, Portugal

Large US research institution,

University of Rhode Island, USA

Petra Christian University, Indonezia

University of Limerick, Ireland

COMSATS Institute of Information Technology, Islamabad-Pakistan.

Belarusian National Technical University, Belarus

Aligarh Muslim University, India

Federal University of Minas Gerais (Brazil)

Penn State University, USA

Fundacao Escola de Sociologia e Politica de Sao Paulo - FESPSP, Argentina
Africa

$\mathrm{EU}$

South

America

Arabia

$\mathrm{EU}$

Asia

$\mathrm{EU}$

$\mathrm{EU}$

USA

USA

Asia

EU

Asia

Eurasia

Asia

South

America

USA

South

America

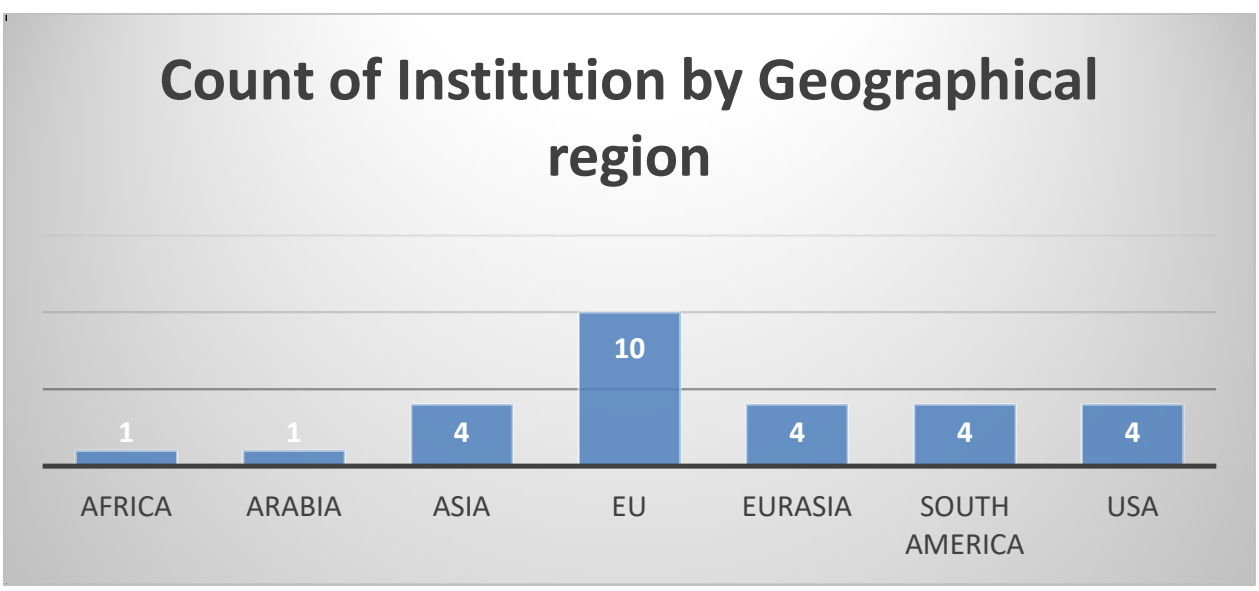

Fig. 10. Geographic spread of the respondents

Most of the respondents, $54,35 \%$ are librarians, academic staff is represented by $34,78 \%$, 6,52\% are Ph.D. students , 2,71\% master students, and other situations 2,17\%. (Fig.11) The sample is very well structured consisting mostly of librarians but academic staff is also very well represented. 
Q13

You are:

Answered: 46 Skipped: 0

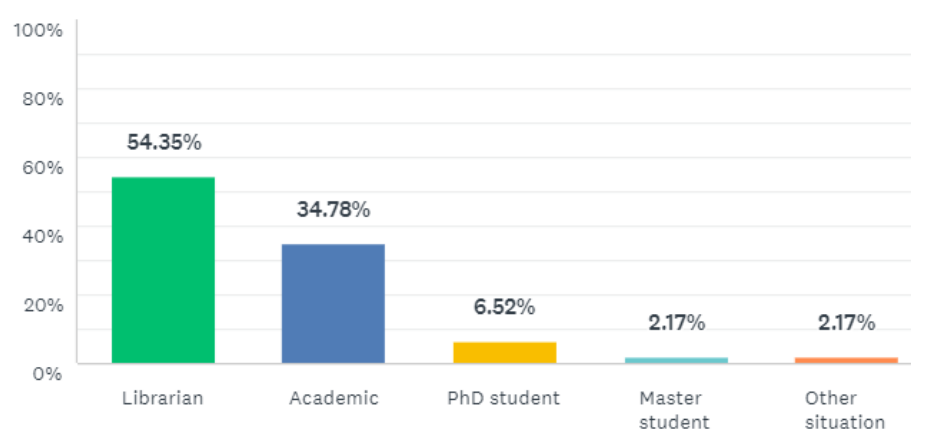

Fig. 11. Respondents profession

The sample structure is well balanced from the point of view of the activity type, $45,65 \%$ are persons involved in libraries management, $43,48 \%$ are not involved in management and 10,87\% are involved in the university management.(Fig. 12)

Q14

You are in:

Answered: 46 Skipped: 0

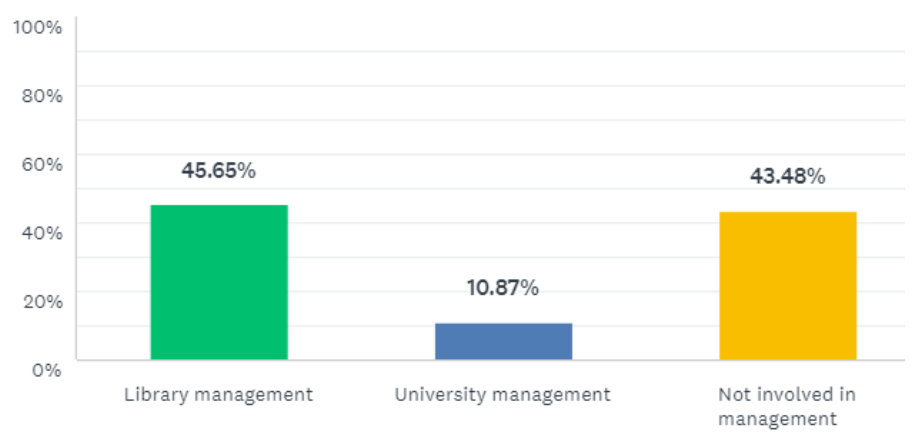

Fig. 12. Respondents involvement in management

$71,74 \%$ are female respondents and only $28,26 \%$ are male respondents. (Fig. 13) 


\section{Your gender:}

Answered: 46 Skipped: 0

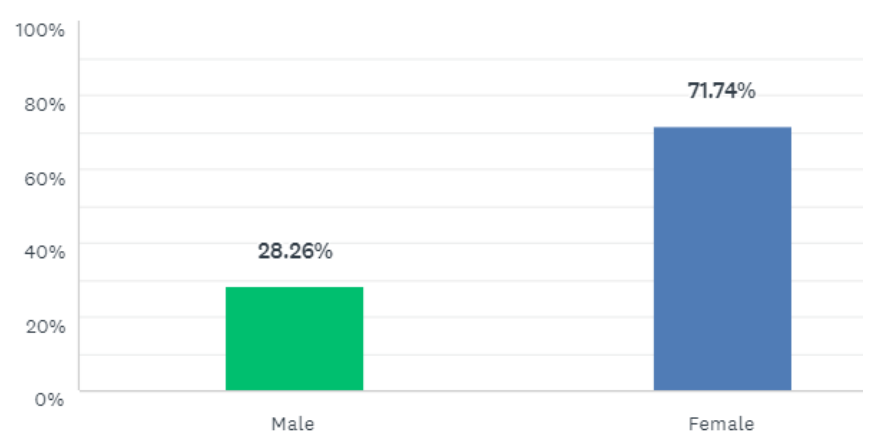

Fig. 13. Respondents gender distribution

\section{Q16: If you have any other comments, suggestions or requests please provide} details below:

The comments provided were highly objective and a selection is presented below:

- I believe that bibliometrics can be ONE of the appropriate ways to measure scientific production, if practiced by experts and with respect to the peculiarities of each scientific field;

- Researchers and librarians need knowledge of bibliometry and scientometry;

- The elements of bibliometrics are already being implemented in our institution. However, I think it will have to become a strategic objective of the university;

- Bibliometrics not understood by many in the academic community and there is little awareness within Librarianship;

- Apart from quantitative analysis qualitative aspect also need to focus;

- This is a coming hot topic for library research services. We live in an increasingly assessment -driven that academics understand and until a viable alternative presents itself, it is the best system we have. I think the library profession needs to develop greater expertise in bibliometrics, data management and research skills;

- Bibliometrics is undervalued and because there is lack of international standardized guidance, the level of analysis may vary a lot in different libraries. Including bibliometric work should be included in the statistics of scientific libraries because it may take a lion part of an information specialists;

- Relative to question number 5, I do not think that bibliometrics are appropriate for measuring production but instead impact, so my issue with the question is more semantic than substantive.

- Culture. This need to use evidence for impact of faculty and of universities will not likely go away;

- Combining bibliometrics with newer metrics (Altmetrics, etc.) will be very interesting;

- While I am aware that there are many flaws to the journal ranking system and corresponding bibliometrics, I am also aware that it is the language. 


\section{Discussions and conclusions}

The awareness regarding bibliometrics and the importance of this branch of information science is at an acceptable level in the education and research institutions and also in libraries. Most of the respondents, that is $92 \%$ have a certain awareness level regarding bibliometrics.

$90 \%$ of the respondents agree that bibliometrics is important for libraries. This result indicates the fact that libraries should be involved in the decision-making process regarding the collections development, in scientific research by research activity or as support institutions.

A slightly smaller number of respondents consider bibliometrics is important in scientific research evaluation with respect to those considering bibliometrics important for libraries.

Scientific production is one of the most used indicators in scientific research evaluation. In case of countries evaluation and classification, most classification systems take into consideration the scientific production of countries, universities, researchers.

Most of them agree that Bibliometrics is an important subject and should be included in every curriculum of LIS schools.

The fact that there is a $50 \%$ share of institutions where the bibliometrics service is offered and in $50 \%$ of the institutions there is no such service shows that bibliometric researches are still not a priority of the institutions and these indicators are used even without a specialized service.

\section{References}

Lotka, A. J. "The frequency distribution of scientific productivity." Journal of the Washington Academy of Sciences 16(12) (1926): 317-324.

Hulme, E. W. Statistical bibliography in relation to the growth of modern civilization. London, 1923.

Pritchard, A. "North-Western Polytechnic, London, Now at National Computing Centre." Manchester, Journal of Documentation 25(4) (1969): 348-349.

Abramo, Giovanni, and Ciriaco Andrea D'Angelo. 2014. "How Do You Define and Measure Research Productivity?” Scientometrics 101 (2): 1129-44. doi:10.1007/s11192014-1269-8.

Bihari, Anand, and Manoj Kumar Pandia. 2015. "Key Author Analysis in Research Professionals' Relationship Network Using Citation Indices and Centrality." Procedia Computer Science 57. Elsevier Masson SAS: 606-13. doi:10.1016/j.procs.2015.07.414.

Nalimov, V. V., and G. Colodny. n.d. Life and the Probabilistic, Edited by Robert, Reality, New, Svetlana Maltseva, and Svetlana Maltseva. 2013. "Professor V . V . Nalimov: A Man Who Surpassed His Time," 3-6.

Wilsdon, James, Judit Bar-Ilan, Robert Frodeman, Elisabeth Lex, Isabella Peters, and Paul Wouters. "Next-Generation Metrics," 26 (2017). doi:10.2777/337729. 